\title{
Set-up of a dynamic in vitro exposure device for the study of indoor air pollutant effects on human derived cells
}

\author{
F. Pariselli, M. G. Sacco \& D. Rembges \\ European Commission, Joint Research Centre, \\ Institute for Health and Consumer Protection, \\ Physical and Chemical Exposure Unit, Ispra, Italy
}

\begin{abstract}
Exposure to air pollutants such as volatile organic chemicals (VOCs) is recognized as a potential cause of allergies, asthma, mucous irritation, headaches and tiredness and may substantially contribute to the increase of cancer incidence in the population. Their presence is not limited to urban and workplace environment but in homes, offices, schools, and hospitals at concentrations often much higher than outdoors. As the number of chemical products created is still increasing, the study of the toxic effects of VOC mixtures requires the development of an effective and reproducible technique for in vitro exposure of cell culture to air pollutants as an alternative tool to in vivo tests. The aim of this work was to develop an in vitro exposure set-up for the assessment of the toxicity of single volatile chemicals and their mixtures on representative VOCs target tissues: skin and lung. We used a dynamic exposure module, named CULTEX $^{\circledR}$, where human derived cell lines from lung epithelium (A549) and keratinocytes $(\mathrm{HaCaT})$ were exposed in an air/liquid interface to a low flow of air pollutants mixture as a close simulation of in vivo exposure. Exposure to toluene or benzene concentrations showed reproducible and dose-related direct toxic effects on both cell lines. Moreover, benzene or toluene induced an inflammatory response. The results obtained so far show the sensitivity and specificity of the overall CULTEX ${ }^{\circledR}$ exposure module that could allow one to conduct further investigations on the effects of mixture of air pollutants on these representative target tissues.
\end{abstract}

Keywords: dynamic exposure device, inflammatory response, in vitro cytotoxicity, volatile organic compounds. 


\section{Introduction}

Volatile organic compounds (VOCs) are important indoor air contaminants that are evaporated into the atmosphere at room temperature. Recent studies highlight the fact that exposure to these volatile organic compounds are more important indoors that outdoors. Emission sources of VOCs are stored household products (white spirit, paint, glue...) and common household activities (e.g., painting, staining, varnishing) that can produce air concentrations of VOCs as high as $1000 \mathrm{mg} / \mathrm{m}^{3}$. Benzene is a well-known carcinogen that has been causally linked to leukaemia. The major source of exposure to benzene arises from cigarette smoke that accumulates inside homes, offices and vehicles [1, 2]. Although toluene and xylene are not currently classified as carcinogens, it was reported an increase of cancer incidence in paint industry workers with long-term exposure to these organic solvents. Furthermore, increased risk for esophageal cancers was suspected to be related to occupational exposure to toluene and xylene. Hence, there is a pressing need to find "stress indicators" to rigorously evaluate the impact of these xenobiotics on biological processes [3].

The aim of this work was to set-up an in vitro exposure model in order to evaluate toxicological properties of single volatile chemicals and their mixtures characteristic of indoor-air environment. Since the target tissues for VOCs toxicity are lungs and the skin, the cell lines chosen for this purpose were human tumor bronchial epithelial cells (A549) and human keratinocytes (HaCaT). This study started with the application of priority air pollutants, which were selected in the frame of the European INDEX project ("Critical appraisal of the setting and implementation of European INDoor EXposure limits") [4]. Toluene and benzene were chosen as first air pollutants to set-up the exposure technique as they are known to induce lung and dermal toxicity.

\section{Materials and methods}

\subsection{Cell culture conditions}

Experiments were carried out with two human derived cells lines: lung epithelial carcinoma cell line (A549) and keratynocyte derived cell line (HaCaT). They were both cultivated in RPMI 1640 medium, supplemented with fetal calf serum (FCS) $10 \%, 100 \mathrm{unit} / \mathrm{ml}$ penicillin and $100 \mu \mathrm{g} / \mathrm{ml}$ streptomycin (Invitrogen; USA) at $37^{\circ} \mathrm{C}$ under humidified atmosphere containing $5 \% \mathrm{CO}_{2}$. For exposure experiments, cells were harvested with trypsin, counted and seeded onto cell culture inserts with track-etched polyethylene teraphtalate (PET) membranes permeable to culture medium (Becton Dickinson; USA). At confluence, the culture medium was removed and cells were seeded with RPMI 1640 medium without serum for $24 \mathrm{~h}$. Before exposure, insert were washed two times and transferred into the exposure device. Here inserts are only immersed in medium to feed the cells from the basal side with medium without FCS and exposed to atmosphere at their apical side until the end of the experiment ( 1 to 2 hours). After exposure experiments, inserts were transferred into conventional plates, fed 
on both side by medium supplemented with 1\% FCS and antibiotics and incubated $24 \mathrm{~h}$ before further measurements.

\subsection{Chemical compounds}

As test atmospheres we used synthetic air (80\% nitrogen, $20 \%$ oxygen), benzene (1 ppm, balanced with nitrogen) or toluene (1 ppm, balanced with nitrogen) purchased from Air Liquide (France). Chemicals and reagents for biochemical analysis were obtained from Sigma (USA).

\subsection{Cell exposure device: CULTEX ${ }^{\circledR}$ system}

The CULTEX ${ }^{\circledR}$ system (Vitrocell, Germany) [5] is based on the use of cell culture inserts which offer the unique possibility of culturing cells on membranes permeable to culture media and to expose them to a dynamic flow of atmosphere at their air/liquid interface as it occurs in the in vivo environment. This system is made out of glass and stainless steel and consists of two parts. The lower part is a culture chamber maintained at $37^{\circ} \mathrm{C}$ that can hold separately three inserts and can provide medium supply. Here inserts are only immersed in medium; the medium on the apical side was removed and cells were exposed to the test atmospheres at their air/liquid interface until the end of the experiment. The upper part of the device houses the tube system for the transport of test atmosphere and seals the lower part. Figure 1 shows how insert cell culture is exposed to test atmosphere when the device is sealed; the gases are conducted by a trumpet-shaped tube on the surface of cell monolayer and leave each insert from corresponding hole by negative pressure. This system guarantees a continuous flow and an equal distribution of gases in the three inserts and on the entire surface of the culture.

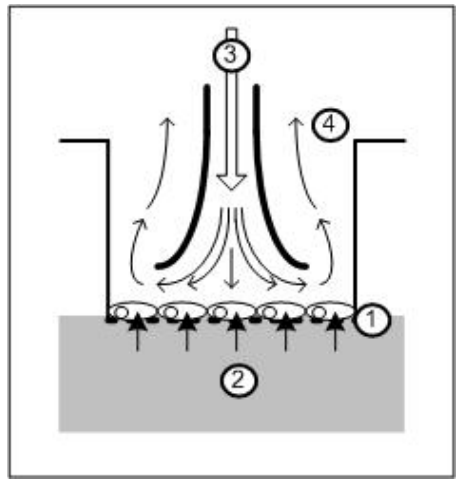

Figure 1: Cell exposure scheme. 1: Cells grown into inserts on microporous membrane, 2: culture medium supply, 3: exposure gas flow conducted very close to the cells, 4: gas outlet drove by negative pressure. 
For exposure experiments, the CULTEX ${ }^{\circledR}$ device was connected to a system of test atmosphere generation and conduction (Figure 2). The test atmosphere was generated by mixing synthetic air with different doses of air pollutants and conducted trough the CULTEX ${ }^{\circledR}$ ( 1 to $2 \mathrm{ml} / \mathrm{min} /$ inserts) by a negative pressure set by vacuum pump and a mass-flow controller (Bronkhorst, Netherlands).

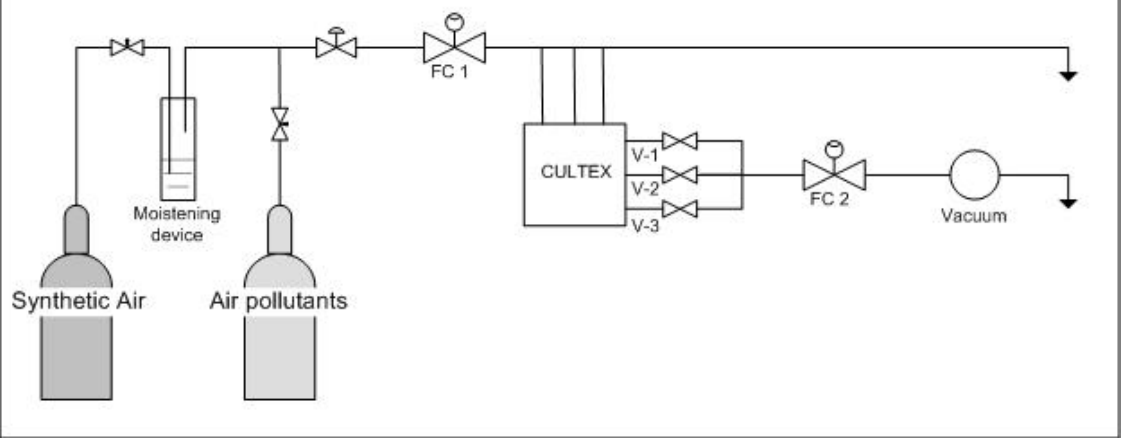

Figure 2: Scheme of generation and conduction of test atmospheres. (FC: flow controller, V: valve).

\subsection{Endpoints}

Cell viability was evaluated with two different methods. The dosage of the lactate deshydrogenase (LDH) released from cells only upon damage of the cytoplasmique membrane is an index of cell membrane integrity and for extension of cytotoxicity. LDH was measured by a spectrophotometric method, reading the kinetics of NADH oxidation as a decrease of absorbance at $340 \mathrm{~nm}$. The percentage of toxicity was calculated as percentage of $\mathrm{LDH}$ released in the medium on the total LDH (i.e. medium + cells). The cell proliferation assay WST-1 (Roche Applied Science, USA) contains tetrazolium salt cleaved to a soluble formazan dye by mitochondrial enzyme active only in viable cells. Total activity of this mitochondrial enzyme in a sample rises with the increase of viable cells. As the increase of enzyme activity leads to an increase of the production of formazan dye, the absorbance of formazan dye in the medium is proportional to the number of viable cells. The formation of formazan is measured after 3hours of incubation in the medium at $37^{\circ} \mathrm{C}$ by a spectrophotometer at $405 \mathrm{~nm}$. In order to evaluate inflammatory response after exposure with priority pollutants, Interleukin-8 (IL-8) has been chosen as a proinflammatory biomarker. It was measured in medium $24 \mathrm{~h}$ after exposure by an ELISA test (Pierce, USA).

\subsection{Controls}

As cell integrity control we used inserts with cells in normal culture conditions (with media on both sides) left during the exposure time in the incubator $\left(37^{\circ} \mathrm{C}\right.$, 
$5 \% \mathrm{CO} 2,100 \%$ humidity). Synthetic air exposed inserts were used as control for the air pollutant exposures. Inserts left in the incubator during 1 hour without media on the apical side gave the same results than those with medium on both sides (data not shown).

\subsection{Atmosphere test analysis}

Before and after each exposure experiment, sampling of test atmosphere were made before entering the CULTEX ${ }^{\circledR}$ and analysed by gas chromatography/mass spectrometry (GC-MS HP 5890, Finnigan).

\subsection{Statistical analysis}

Exposures were always carried out in triplicate and experiments were repeated at least three times. Data are presented as the mean \pm S.E.M. and statistically analysis was carried out with the Student $t$ test.

\section{Results}

\subsection{Set-up of the exposure conditions}

A particularity attention was made on healthy conditions of the cell culture during exposure experiments. In order to keep humidity level and $\mathrm{pH}$ of medium constant, we used a moistening device connected between the synthetic air delivery and the exposure device (see figure 2) and an HEPES buffered medium. Moreover, the CULTEX ${ }^{\circledR}$ device housed a warmed water jacket in order to keep cells and culture medium at $37^{\circ} \mathrm{C}$.

Flow rate of test atmosphere and exposure time were also determined in order to minimize mechanical stress or dehydration of the cell monolayer and to keep cell viability as higher as possible after exposure. Several experiments with different flow rates ( 1 to $8 \mathrm{ml} / \mathrm{min}$ ) and different exposure times (from 60 to 120 minutes) were performed with the A549 cell line. We obtained the best results evaluated with $\mathrm{LDH}$ and WST-1 assay (viability $>90 \%$ ) with a synthetic airflow rate from 1 to $2 \mathrm{ml} / \mathrm{min}$ in each insert for an exposure time from 60 to 120 minutes (data not shown).

Table 1: Cell viability and cytotoxicity of human derived cells $24 \mathrm{~h}$ after exposure to synthetic air with WST-1 and LDH assays.

\begin{tabular}{|c|c|c|c|c|c|c|c|c|}
\hline \multirow[b]{2}{*}{ Cell line } & \multirow[b]{2}{*}{ Treatments } & \multicolumn{2}{|c|}{$\begin{array}{l}\text { Cell viability } \\
\text { (WST-1 assay) }\end{array}$} & \multicolumn{4}{|c|}{$\begin{array}{l}\text { Cytotoxicity } \\
\text { (LDH assay) }\end{array}$} & \multirow[b]{2}{*}{$t$ test } \\
\hline & & $\% \pm$ S.E.M. & $\mathrm{n}$ & $t$ test & & $\begin{array}{l}\% \pm \\
\% . M .\end{array}$ & $\mathrm{n}$ & \\
\hline \multirow{2}{*}{ A549 } & Control & $100 \quad 0.0$ & 14 & & 5.7 & 0.8 & 9 & \\
\hline & Synthetic air exposure & $98 \quad 1.0$ & 27 & NS & 8.0 & 1.0 & 27 & NS \\
\hline \multirow{2}{*}{$\mathrm{HaCaT}$} & Control & $100 \quad 0.0$ & 17 & & 7.1 & 0.2 & 4 & \\
\hline & Synthetic air exposure & $85 \quad 5.0$ & 35 & $\mathrm{~S}$ & 14.3 & 1.5 & 4 & $\mathrm{~S}$ \\
\hline
\end{tabular}

NS: not significant; S: significant $\mathrm{p}<0.005$ 
In order to validate culture and exposure conditions with the CULTEX ${ }^{\circledR}$ device, we performed repeated synthetic air exposure with a $2 \mathrm{ml} / \mathrm{min}$ flow during 1 hour on both cell lines and evaluated cytotoxicity endpoints after $24 \mathrm{~h}$. Results are presented in table 1. Exposure of A549 cell line to synthetic air shows no statically significant differences $(p>0.05)$ with respect to the control with both tests. With the HaCaT cell line, we reached about $85 \%$ of survival (WST-1 assay) for cells exposed to synthetic air; moreover, the results obtained with LDH assay show statistically significant differences between control and exposed cells.

\subsection{Effects of toluene exposure}

Cells were exposed under airlifted conditions with a mixture of synthetic air and toluene with a $2 \mathrm{ml} / \mathrm{min}$ flow for 1 hour in the CULTEX $^{\circledR}$ device. At the end of the exposure, cells were left on the inserts to recovery for 24 hours in the $\mathrm{CO}_{2}$ incubator with fresh medium (with $1 \%$ FCS) on both sides before LDH assay and IL-8 released determination. The range of toluene concentration determined with Tenax ${ }^{\circledR}$ sampling and gas chromatography was ranging between 0.1 and $0.6 \mathrm{ppm}$. The average cytotoxicity of the A549 and HaCaT cell lines exposed to toluene are summarized in figure 3. For both cell lines, exposure to toluene concentration ranging from 0.1 to $0.6 \mathrm{ppm}$ reduced significantly the viability after 24 hours when compared with the control. Toluene exposure stimulated significantly the IL-8 release from both cell lines. These results are summarized in figure 4.

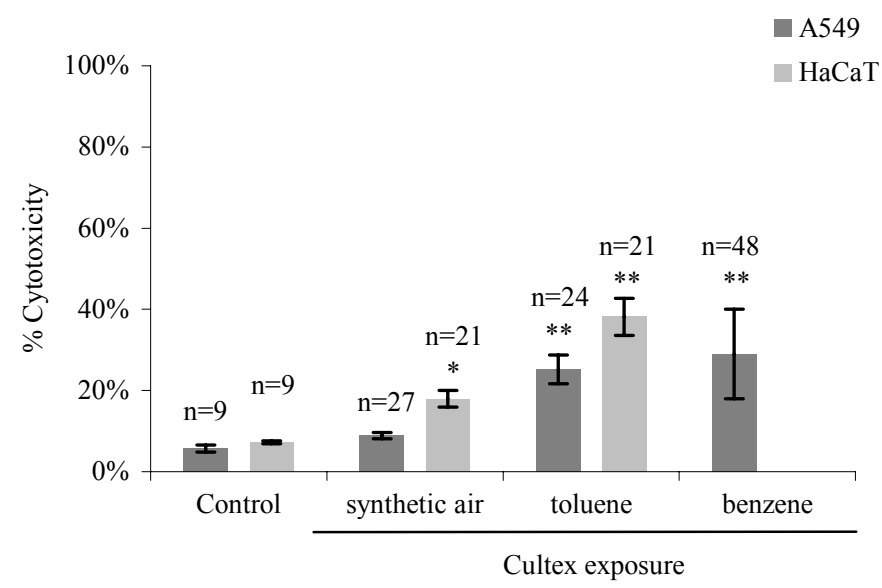

Figure 3: LDH cytotoxicity assay on A549 and HaCaT cell lines exposed to synthetic air, toluene $(0.1$ to $0.6 \mathrm{ppm})$ or benzene $(0.1$ to $0.3 \mathrm{ppm})$ in the CULTEX $^{\circledR}$ device. *Statistically significant from control $(\mathrm{p}<0.005) . * *$ Statistically significant from control and synthetic air exposure $(\mathrm{p}<0.0005)$. 


\subsection{Effects of benzene exposure}

Cells were exposed to benzene with the same experimental conditions used for toluene. Here only A549 cell line was tested. The range of benzene concentration was between 0.1 to $0.3 \mathrm{ppm}$. Cytotoxic effect and IL-8 released induced by benzene exposure were summarized in figure 3 and 4.

Exposure to benzene reduced significantly the viability of A549 cell line after 24 hours and increased significantly the release of IL-8 in the culture medium.

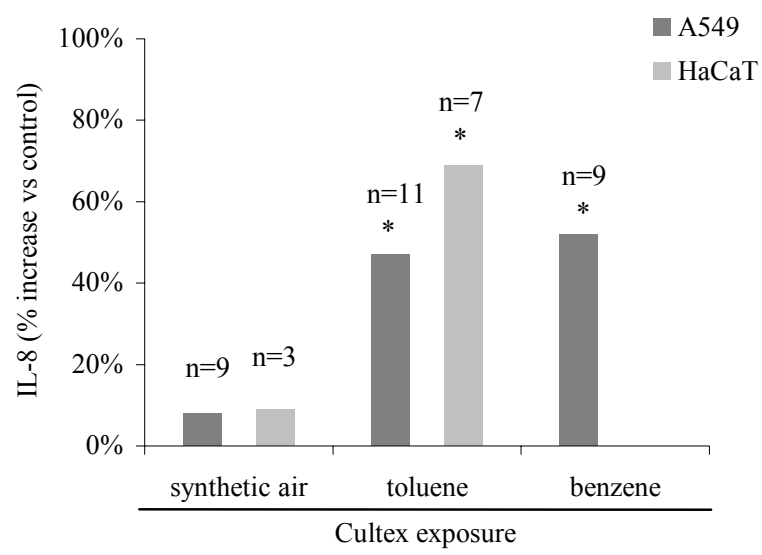

Figure 4: IL-8 release determination with A549 and HaCaT cell lines exposed to synthetic air, toluene ( 0.1 to $0.6 \mathrm{ppm})$ and benzene ( 0.1 to $0.3 \mathrm{ppm})$ with the CULTEX ${ }^{\circledR}$ device. *Statistically significant from control $(\mathrm{p}<0.005)$.

\section{Conclusion}

The aim of this work was to set-up a dynamic in vitro exposure model and to evaluate toxicological properties of priority air pollutants (VOCs) as single components in order to extend further studies on the effects of the indoor air pollutants mixtures on human derived cells. CULTEX ${ }^{\circledR}$ device was used to expose to chemicals in air/lifted interface representative of VOCs' target tissues: human lung and dermal cell lines (A549 and $\mathrm{HaCaT}$ ).

In order to use healthy cells in optimal conditions and to obtain reproducible results several requirements were met for the exposure experiments [6]: The system is designed in order to keep cells in optimal conditions during their maintenance in an air/liquid interface; i.e. temperature and $\mathrm{pH}$ of the medium should be constant and the atmosphere must be humid, so that extended exposure is possible. The system has a precise control of atmosphere generation and measurements with mind on the purity of the air supply. The gases are in contact with cells as closely as possible to mimic in vivo conditions, avoiding the 
presence of medium, since gases could react with its components and toxic effects may be masked. Sterile conditions are maintained during exposure, since bacterial or fungal contaminations could easily affect cellular metabolism and lead to erroneous conclusions. For these reasons several culture conditions parameters were defined before and during the exposure (airflow, exposure time, pH buffer, moistening) allowing us to keep cells in better conditions and to decrease some mechanical effects which can damage them. This was achieved for A549 cell line, while further improvements are necessary for HaCaT cell line. Exposure experiments performed with toluene or benzene showed reproducible direct toxic effects on cell cultures for both cell lines. The increasing LDH cytotoxicity from $0.1 \mathrm{ppm}$ toluene exposure to $0.6 \mathrm{ppm}$ gave first indications of a dose related response. Similar results were obtained for A549 cells exposed to benzene $(0.1$ to $0.3 \mathrm{ppm})$. Further exposure experiments with different concentrations of toluene and benzene have to be worked out for validating this hypothesis. In addition, we demonstrated the ability of toluene and benzene to induce an inflammatory response (IL-8 stimulation), according to data reported in literature [7, 8].

In vitro exposure systems have several advantages: toxic agents that cannot be used in animal for ethical and financial reasons can be tested, individual cell type response to pollutants permits better determination of the independent contribution of this cell type to a particular response, a number of human cell lines, tissues or primary cell lines can be used and as the exposure conditions were rigorously controlled they can easily be reproduced [9]. Moreover, this dynamic exposure system has the advantage to test volatile chemicals alone or in a complex mixture, soluble or insoluble and particularly in experimental conditions that closely simulate the exposure of target tissues in vivo.

Summarizing, all these results show the sensitivity and specificity of the over all CULTEX ${ }^{\circledR}$ exposure set-up and this will be the basis to perform exposure treatments to air pollutants alone or in mixtures.

\section{Acknowledgements}

The authors would like to acknowledge the technical assistance of Mr. T. Krebs from the Vitrocell Company, Mr. A. Collotta for his skillful technical assistance and Mr. P. Leva, A. Katsogiannis and O. Geiss from the PCE unit (JRC, IHCP) for all air pollutants determination.

\section{References}

[1] Wallace, L., Environmental exposure to benzene: an update. Environ Health Perspect, 104(6), pp. 1129-1136, 1996.

[2] Wallace, L., Major sources of benzene exposure. Environ Health Perspect, 82, pp. 165-169, 1989. 
[3] Sikkema, J., de Bont J.A. and Connell, D.W., Interactions of cyclic hydrocarbons with biological membranes. J Biol Chem, 269, pp. 8022-8028, 1994.

[4] Kotzias, D., Koistinen, K., Kephalopoulos, S., Schlitt, C., Carrer, P., Maroni, M., Jantunen, M. Cochet, C., Kirchner, S., Lindvall, T., McLaughlin, J., Mølhave, L., de Oliveira Fernandes, E., Seifert, B. Final Report of the INDEX project, Critical Appraisal of the Setting and Implementation of Indoor Exposure Limits in the EU. EUR 21590 EN 2005, 2006. www.jrc.cec.eu.int/pce/documentation_reports.htm

[5] Aufderheide, M. and Mohr, U., CULTEX - a new system and technique for the cultivation and exposure of cells at the air/liquid interface. Exp Toxicol Pathol, 51, pp. 489-490, 1999.

[6] Rassmussen, R.E., In vitro systems for exposure of lung cells to $\mathrm{NO}_{2}$ and $\mathrm{O}_{3} . J$ Toxicol Environ Health, 13(2-3), pp. 397-411, 1984.

[7] Chou, C.C., Riviere J.E. \& N.A., The cytotoxicity of jet fuel aromatic hydrocarbons and dose-related interleukin- 8 release from human epidermal keratinocytes. Arch Toxicol, 77, pp. 384-391, 2003.

[8] Kawasaki, S. et al., Benzene-extracted components are important for the major activity of diesel exhaust particles: effect on interleukin-8 gene expression in human bronchial epithelial cells. Am J Respir Cell Mol Biol, 24(4), pp. 419-426, 2001.

[9] Wallaert, B., Fahy, O., Tsicopoulos, P., Gosset, P. and Tonnel, A.B., Experimental systems for mechanistic studies of toxicant induced lung inflammation. Toxicol Lett, 112-113, pp. 157-163, 2000. 